\title{
Correction to: Disability-adjusted life years and mortality rate attributed to unsafe sex and drug use for AIDS in the Middle East and North Africa countries
}

Farid Najafi ${ }^{1,2+}$, Fatemeh Khosravi Shadmani ${ }^{1+}$, Mojtaba Ghalandari ${ }^{3,4}$ and Mitra Darbandi ${ }^{1 *}$

\section{Correction to: Arch Public Health 78, 130 (2020) https://doi.org/10.1186/s13690-020-00511-1}

Following publication of the original article [1], the authors identified an error in the author name of Fatemeh Khosravi Shadmani

- The incorrect author name is: Fatemeh Khosravi

- The correct author name is: Fatemeh Khosravi Shadmani

The author group has been updated above and the original article [1] has been corrected.

\footnotetext{
Author details

'Research Center for Environmental Determinants of Health (RCEDH), Health Institute, Kermanshah University of Medical Sciences, Kermanshah, Iran. ${ }^{2}$ Cardiovascular Research Center, Kermanshah University of Medical Sciences, Kermanshah, Iran. ${ }^{3}$ Mahneshan Health Center, Zanjan University of Medical Sciences, Zanjan, Iran. ${ }^{4}$ Department Epidemiology, Public Health College, Kermanshah University of Medical Sciences, Kermanshah, Iran.
}

Published online: 18 January 2021

\section{Reference}

1. Najafi F, Khosravi F, Ghalandari M, et al. Disability-adjusted life years and mortality rate attributed to unsafe sex and drug use for AIDS in the Middle East and North Africa countries. Arch Public Health. 2020;78:130. https://doi. org/10.1186/s13690-020-00511-1.

The original article can be found online at https://doi.org/10.1186/s13690020-00511-1.

* Correspondence: m.darbandi@kums.ac.ir

${ }^{\dagger}$ Farid Najafi and Fatemeh Khosravi Shadmani contributed equally to this work.

'Research Center for Environmental Determinants of Health (RCEDH), Health Institute, Kermanshah University of Medical Sciences, Kermanshah, Iran Full list of author information is available at the end of the article

(c) The Author(s). 2021 Open Access This article is licensed under a Creative Commons Attribution 4.0 International License, which permits use, sharing, adaptation, distribution and reproduction in any medium or format, as long as you give appropriate credit to the original author(s) and the source, provide a link to the Creative Commons licence, and indicate if changes were made. The images or other third party material in this article are included in the article's Creative Commons licence, unless indicated otherwise in a credit line to the material. If material is not included in the article's Creative Commons licence and your intended use is not permitted by statutory regulation or exceeds the permitted use, you will need to obtain permission directly from the copyright holder. To view a copy of this licence, visit http://creativecommons.org/licenses/by/4.0/ The Creative Commons Public Domain Dedication waiver (http://creativecommons.org/publicdomain/zero/1.0/) applies to the data made available in this article, unless otherwise stated in a credit line to the data. 